\title{
APLICAÇÃO DA TÉCNICA COMBINADA FLOCULAÇÃO/ FLOTAÇÃO NO TRATAMENTO DA ÁGUA PRODUZIDA NA INDÚSTRIA DO PETRÓLEO: UTILIZAÇÃO DE FLOCULANTE NATURAL À BASE DE MORINGA OLEIFERA
}

\author{
E. R. B. MAGAlhãeS ${ }^{1}$, J. B. A. PAUlO ${ }^{1}$, E. M. B. D. SOUZA $^{1}$, S. H. G. AZEVEDO ${ }^{1}$, L. M. L. \\ PESSOA $^{1}$, F. B. CARVALHO ${ }^{1}$ \\ ${ }^{1}$ Universidade Federal do Rio Grande do Norte, Departamento de Engenharia Química \\ E-mail para contato: emybatista_eq@hotmail.com
}

\begin{abstract}
RESUMO - O principal efluente da indústria do petróleo é a água produzida, cujo descarte inadequado traz efeitos nocivos ao meio ambiente. $\mathrm{O}$ tratamento convencional para o efluente associa as técnicas de floculação e flotação. Na floculação são utilizados floculantes convencionais que, além do alto custo, são fornecidos com limitada informação técnica. Este trabalho objetiva avaliar o potencial de um floculante alternativo natural à base de Moringa oleifera para o tratamento da água produzida, comparando sua eficiência com dois floculantes normalmente utilizados pela indústria (A e B). O floculante convencional A apresentou 93\% na eficiência de separação do óleo, seguido do floculante B com remoção de $91 \%$. O floculante alternativo natural, apesar de apresentar menor eficiência de separação que àquelas de $\mathbf{A}$ e $\mathbf{B}$, exibiu uma eficiência de separação de, em média, 77\%. Conclui-se que a análise econômica do processo será determinante para a utilização do floculante alternativo.
\end{abstract}

\section{INTRODUÇÃO}

$\mathrm{Na}$ indústria do petróleo, a geração de um grande volume de água produzida está presente em todas as etapas do processo de produção: extração, transporte e refino, o que torna necessário estabelecer e manter uma gestão deste efluente, considerando, inclusive, o seu difícil descarte, dado a sua composição complexa de sais, gotículas de óleos em suspensão, produtos químicos (adicionados nos diversos processos de produção), metais pesados e, por vezes, alguma radioatividade (Silva, 2000). O descarte inadequado deste efluente industrial reflete em ataques à legislação ambiental vigente, assegurada pelas RESOLUÇÕES CONAMA 357/2005, 393/2007 e pela Lei Ambiental 430/2011, e se apresenta como um sério risco ambiental.

Neste cenário, a busca por alternativas nos processos de tratamento que visam melhorar cada vez mais a qualidade da água produzida tratada, incluindo seus reagentes e técnicas, é constante na indústria, almejando prioritariamente a adequação às exigências ambientais.

Atualmente, a indústria do petróleo se utiliza de um processo convencional de tratamento da água produzida, o qual é composto pelas etapas de coagulação/floculação e flotação, a fim de 


\section{9 a 22 de outubro de 2014 \\ Florianópolis/SC}

diminuir a turbidez e o teor de óleos e graxas (TOG) presentes nessa água. A água tratada, então, é descartada ou, por vezes, reutilizada, quando a qualidade final está adequada para reuso.

A Moringa oleifera é um coagulante natural efetivo, o qual pode ser usado no tratamento de água. Sua ação coagulante reside na presença de proteínas catiônicas em suas sementes, as quais são solúveis em água, e apresenta mecanismo de coagulação baseado na adsorção e neutralização de cargas (Ndabigensere et al., 1995).

Diversos estudos foram desenvolvidos com o extrato das sementes da Moringa, comprovando sua eficiência como um agente floculante na preparação do tratamento da água produzida através de flotação por ar dissolvido. Há relatos na literatura de um percentual de remoção de mais de $90 \%$ do teor de óleos e graxas quando a água se apresenta bastante concentrada em óleo. Na clarificação de águas de baixa turbidez utilizando o floculante à base de Moringa seguida da flotação por ar dissolvido, a eficiência de remoção total de turbidez é de 74\%. Estes estudos colocam a Moringa como alternativa aos floculantes comerciais, já que os resultados mostraram que a ação coagulante do extrato das sementes dessa planta é efetiva para processos de tratamento de água produzida através da flotação por ar dissolvido (Santana, 2009; Lédo, 2008; Paulo et al., 2013).

Esse trabalho tem como objetivo, portanto, avaliar o potencial do floculante alternativo natural à base de Moringa oleifera na remoção de óleos e graxas da água produzida pelas etapas de floculação e flotação por ar dissolvido quando comparada a dois floculantes comumente utilizados pela indústria (A e B).

\section{MATERIAIS E MÉTODOS}

\section{1. Água produzida semi-sintética}

A água produzida utilizada no desenvolvimento deste estudo foi adquirida junto a uma ETE da UO-RNCE que realiza tratamento em águas produzidas provenientes de campos off-shore. As condições e o tempo de transporte resultam em redução natural do teor de óleos e graxas (TOG) presentes na água a ser tratada, uma vez que pode ocorrer uma separação espontânea entre o óleo e a água. Assim sendo, a amostra recebida no Laboratório, pode apresentar condições de TOG não condizentes com a realidade da indústria. Faz-se necessário portanto, adequar a água as reais condições industriais. Neste sentido, uma etapa preliminar de agitação e dosagem de óleo bruto à matriz aquosa foi realizada. Como consequência tem-se uma amostra semi-sintética de água produzida. Óleo bruto foi adicionado à água e a mistura foi submetida à agitação por $2 \mathrm{~h}$, objetivando uma concentração de óleos e graxas entre 70 a 110 ppm.

\subsection{Reagentes Utilizados}

Os reagentes utilizados nos ensaios de floculação/flotação foram: sementes de Moringa oleífera (colhidas no campus universitário da UFRN), floculantes A e $\mathbf{B}$ (floculantes comerciais fornecidos pela Petrobras cujos nomes não serão divulgados por respeito à política de confidencialidade) e hexano grau UV/HPLC (para as medidas de TOG das amostras). 


\section{9 a 22 de outubro de 2014 \\ Florianópolis/SC}

\subsection{Propriedades físico-químicas da água produzida}

A caracterização da água produzida, no que diz respeito aos parâmetros físico-químicos de qualidade, foi realizada com a Sonda Multiparamétrica, marca In-Situ - modelo TROLL 9500, existente no Laboratório de Monitoramento e Tratamento de Resíduos da Indústria do Petróleo (LAMTRE).

\subsection{Preparação do floculante alternativo natural}

As sementes de vagens secas de Moringa oleifera foram descascadas manualmente, trituradas até se obter um pó fino e submetidas a um processo de extração para a retirada do óleo. O pó seco obtido a partir dessas etapas foi misturado à água destilada na proporção de $1 \mathrm{~g}$ para $50 \mathrm{~mL}$ de água. A mistura obtida foi batida em um mixer por cinco minutos e levada à filtração à vácuo através de um papel de filtro de $5-7 \mu \mathrm{m}$. O filtrado obtido foi utilizado como floculante alternativo natural (Okuda et al., 1999; Paulo et al., 2013).

A determinação da concentração da solução do floculante alternativo à base de Moringa foi dada através da secagem da torta na estufa a $100{ }^{\circ} \mathrm{C}$ por cerca de 6 horas, a fim de eliminar toda a água presente. $\mathrm{O}$ pó seco obtido foi então pesado e, por balanço de massa, determinada a massa de Moringa presente na solução.

Com o objetivo de manter a ação coagulante total, as sementes utilizadas neste estudo tinham, no máximo, cinco meses de coleta e a solução preparada era utilizada até três dias após a sua preparação, quando submetida à refrigeração (Santana, 2009; Okuda et al., 1999).

\subsection{Análise de Teor de Óleos e Graxas (TOG)}

A variável resposta (dependente) deste estudo foi a eficiência do processo a partir da análise dos teores de óleos e graxas inicial e final. Essa análise foi realizada através do aparelho INFRACAL, modelo HATR-T2 (Figura 3.7), o qual deve ser ligado, no mínimo, uma hora antes do início de sua utilização. O princípio de funcionamento do aparelho é baseado na absorvância de radiação, na região do infravermelho, por parte do extrato gerado na operação de extração líquido-líquido com o solvente hexano.

\subsection{Operação do Flotateste}

Saturação com ar da água de recirculação: corresponde à primeira etapa do processo, na qual a câmara de saturação é cheia com água destilada (cerca de 2/3 do seu volume) e o compressor é acionado para atingir a pressão de $5 \mathrm{kgf} / \mathrm{cm}^{2} \mathrm{em}$ seu interior. Saturou-se a água por cerca de $10 \mathrm{~min}$.

Ensaios de floculação e flotação: as colunas de flotação foram cheias com a água produzida e os floculantes foram dosados a partir de seringas localizadas na lateral das colunas. Para o início da rotação, referente à etapa de mistura rápida do processo, as paletas foram fixadas nos mandris e a rotação ajustada no variador de frequência. O tempo referente a esta etapa foi constante ( 3 min) e 
cronometrado a partir da adição do floculante num rotação de $226 \mathrm{rpm}$. Após este tempo, a rotação foi reduzida a $90 \mathrm{rpm}$, onde se deu início a etapa de mistura lenta (floculação) e cronometrada de acordo com as condições prévias do ensaio realizado. Ao término desta etapa, a agitação foi desligada e as hastes retiradas dos mandris. De forma imediata, as válvulas de cada coluna de flotação foram totalmente abertas, permitindo a injeção da água saturada com ar com a taxa de recirculação prevista, iniciando o processo de flotação por ar dissolvido. Terminada a injeção, o tempo de flotação foi observado e posteriormente se deu a coleta da amostra de água tratada. A Figura 1 apresenta, de forma esquemática, o flotateste.

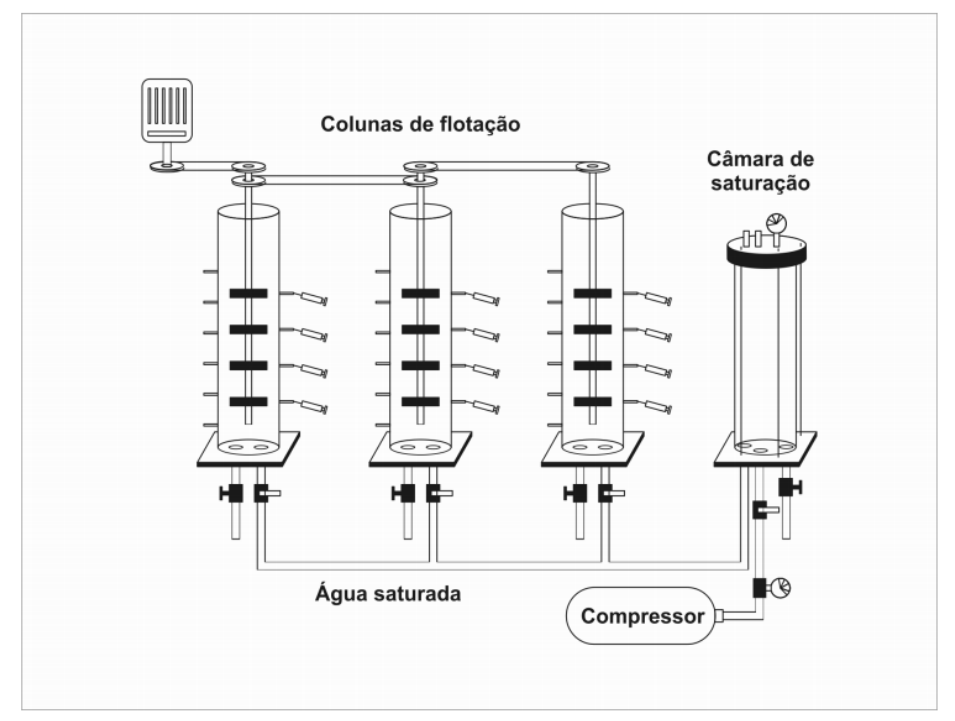

Figura 1 - Esquema do flotateste. Fonte: Lédo, 2008.

\section{RESULTADOS E DISCUSSÃO}

\subsection{Caracterização da água produzida}

A água produzida utilizada nos ensaios de flotação foi caracterizada com a sonda multiparamétrica e apresentou as seguintes propriedades físico-químicas a temperatura de $29{ }^{\circ} \mathrm{C}$ e 1,1 kgf/cm²: turbidez inicial: 29,4 NTU; pH: 6,2; concentração de cloretos: 13263,4 ppm; nitrato: 1880 ppm; condutividade: $86800 \mu \mathrm{S} / \mathrm{cm}$; TOG (Teor de Óleo e Graxas): 10 ppm.

\subsection{Ensaios de floculação/flotação}

Para comparar a eficiência dos floculante à base de Moringa oleifera com os comerciais (convencionalmente usados na indústria) na separação de óleos e graxas da água produzida se utilizou da variação dos seguintes parâmetros:

- Tempo de mistura lenta $\left(\mathrm{T}_{\mathrm{ml}}\right)$ : corresponde à etapa de floculação. É o tempo no qual há a 
formação dos flocos;

- Taxa de recirculação(TR): volume de água saturada com ar injetado nas colunas de floculação/flotação. É a medida indireta da quantidade de bolhas inseridas nas colunas e está relacionado ao percentual de volume de água saturada com ar referente ao volume de água produzida presente na coluna (1L) e

- Tempo de flotação $\left(\mathrm{T}_{\mathrm{f}}\right)$ : tempo no qual o agregado flota à superfície da água tratada.

A conclusão genérica, conforme as curvas apresentadas na Figura 2, é que o floculante A apresentou uma maior eficiência quando comparado ao $\mathbf{B}$ e ao alternativo natural à base de Moringa oleifera, independente das condições dos parâmetros considerados.

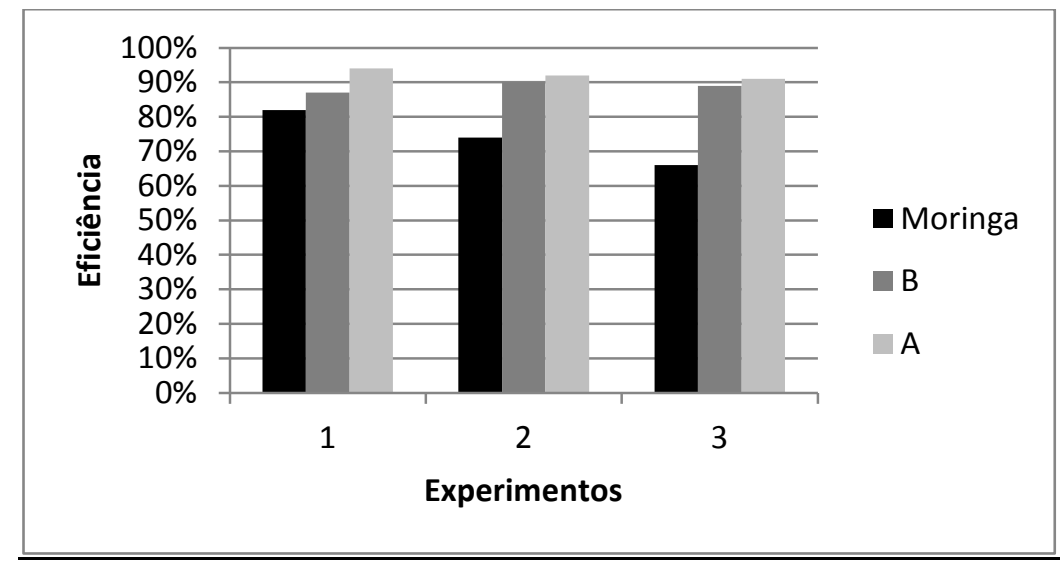

Figura 2 - Curvas da eficiência dos floculantes a 200 ppm em diferentes condições. $1\left(\mathrm{~T}_{\mathrm{ml}}=10 \mathrm{~min} ; \mathrm{T}_{\mathrm{f}}=50 \mathrm{~min} ; \mathrm{TR}=30 \%\right) ; 2\left(\mathrm{~T}_{\mathrm{ml}}=20 \mathrm{~min} ; \mathrm{T}_{\mathrm{f}}=50 \mathrm{~min} ; \mathrm{TR}=50 \%\right)$ e $\mathbf{3}\left(\mathrm{T}_{\mathrm{ml}}=10 \mathrm{~min}\right.$; $\mathrm{T}_{\mathrm{f}}=20 \mathrm{~min} ; \mathrm{TR}=50 \%$ ).

Influência da variação do tempo de mistura lenta: Ao se analisar a influência das variáveis separadamente, tem-se que, ao variar o tempo de mistura lenta (referente à etapa de floculação), todos os floculantes analisados apresentaram maior eficiência quando submetidos ao menor tempo (10 min), de acordo com o esquematizado na Figura 3. Nestes testes, a concentração dos floculantes foi de 200 ppm, o tempo de flotação foi de 50 min e a taxa de recirculação de $50 \%$. 


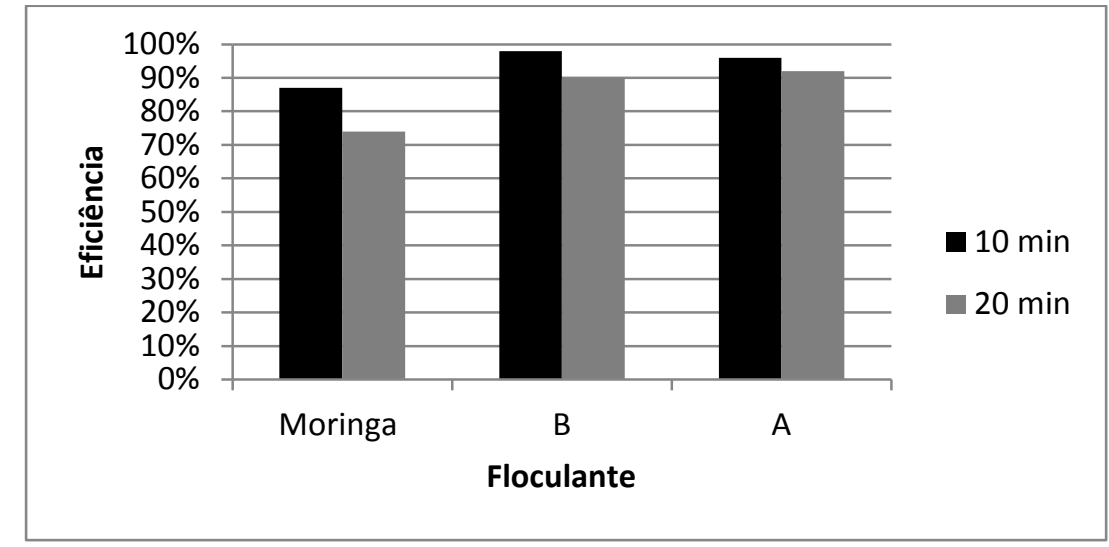

Figura 3 - Eficiência do tratamento da água produzida para os diferentes floculantes utilizados em função do tempo de mistura lenta.

Influência da variação da taxa de recirculação: Com concentração de floculantes a 200 ppm, tempo de mistura lenta de 10 min e tempo de flotação de $50 \mathrm{~min}$, a variação da taxa de recirculação demonstrou que, conforme a Figura 4, o aumento da eficiência se deu com o aumento da taxa para todos os floculantes analisados, tendo um maior efeito para o $\mathbf{B}$ (com uma diferença de 11 pontos percentuais), seguido do alternativo natural à base de Moringa oleifera (diferença de 5\%) e, por último, influenciando em $2 \%$ na atuação do A.

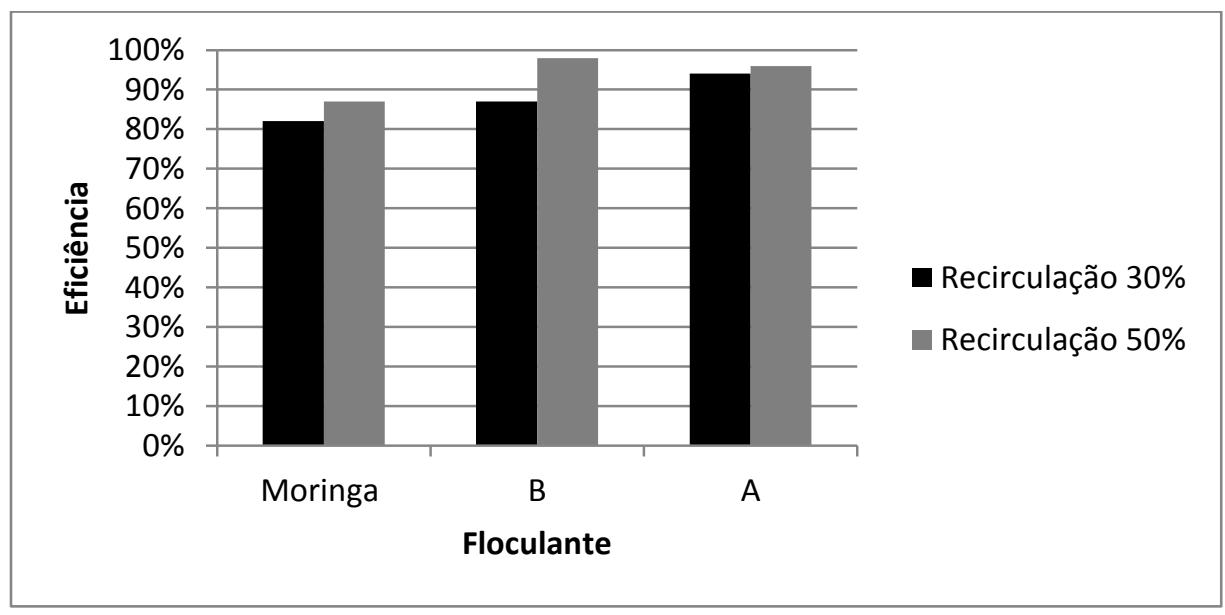

Figura 4 - Eficiência do tratamento da água produzida para os diferentes floculantes utilizados em função da taxa de recirculação. 
Influência da variação do tempo de flotação: Com condições de operação de 200 ppm de concentração de floculantes, tempo de mistura lenta de 10 min e taxa de recirculação de $50 \%$, pode-se afirmar que para todos os floculantes utilizados o aumento de suas respectivas eficiências se deu com o aumento do tempo de flotação, conforme apresenta a curva demonstrada pela Figura 5.

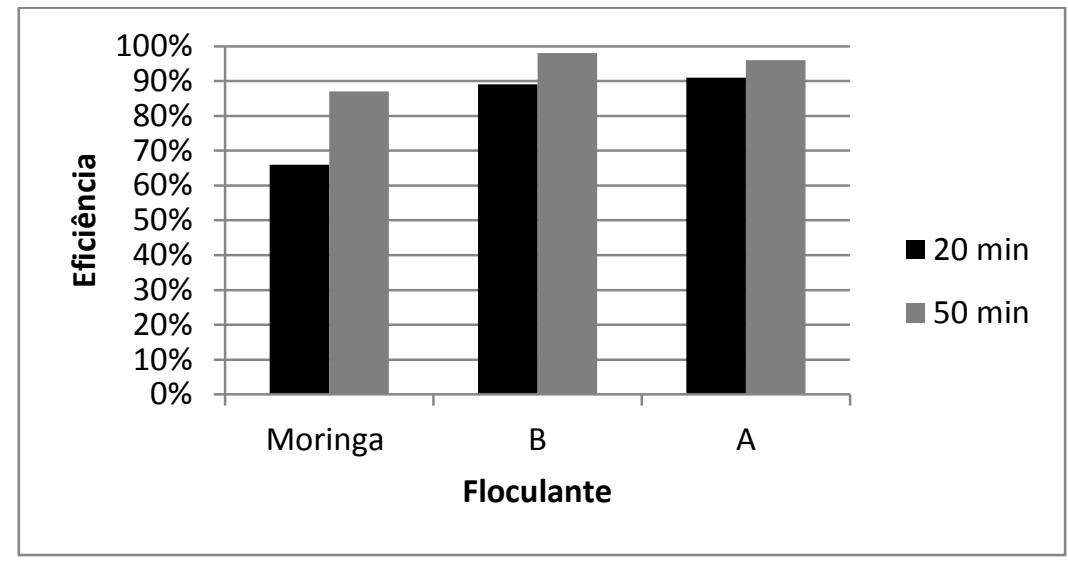

Figura 5 - Eficiência do tratamento da água produzida para os diferentes floculantes utilizados em função do tempo de flotação.

\section{CONCLUSÃO}

Os testes realizados foram capazes de demonstrar que o floculante A se apresentou como o floculante com maior eficiência na separação de óleos e graxas da água produzida quando comparado ao $\mathbf{B}$ e ao alternativo natural à base de Moringa oleifera, chegando a separar mais que 90\% do óleo inicialmente presente na água. O floculante comercial B apresentou uma ótima eficiência, cujo percentual de remoção fica próximo, porém inferior (cerca de $2 \%$ ), ao do A. O polieletrólito natural à base de Moringa oleifera, por sua vez, apesar de uma eficiência menor quando comparado aos outros dois, exibe uma eficiência de separação de, em média, 77\%, chegando a um máximo de $87 \%$, se colocando como uma alternativa real e mais economicamente viável aos floculantes comercialmente utilizados no processo de floculação/flotação para o tratamento de água produzida, sendo a análise econômica do processo, portanto, o determinante para a utilização do floculante alternativo. Em trabalhos futuros deve-se analisar a combinação de floculante comercial com uma proporção em Moringa o que também deverá influenciar na análise econômica do processo.

\section{AGRADECIMENTOS}

Os autores agradecem à Capes e à Petrobras/Cenpes/UO-RNCE pelo suporte financeiro e material para desenvolvimento deste trabalho. 


\section{REFERÊNCIAS BIBLIOGRÁFICAS}

LÉDO, P. G. S. Flotação por ar dissolvido na clarificação de águas com baixa turbidez utilizando sulfato de alumínio e sementes de Moringa oleífera como coagulantes. 2008. 123f. Tese (Doutorado em Engenharia Química) - Centro de Tecnologia, Departamento de Engenharia Química, Programa de Pós Graduação em Engenharia Química, Universidade Federal do Rio Grande do Norte, Natal.

NDABIGENGESERE A.; NARASIAH, K.S.; TALBOT, B.G. Active agentes and mechanism of coagulation of turbid waters using Moringa oleifera. Wat. Res., v.29, n.2, p. $703-710$, Elsevier Science Ltd, 1995.

OKUDA, T.; BAES, A. U.; NISHIJIMA, W.; OKADA, M. Improvement of extraction method of coagulation active components from Moringa oleifera seeds. Wat. Res., v.33, n.15, p. 3373 3378, Elsevier Science Ltd, 1999.

PAULO, J. B. A.; LEDO, P. G. S.; SOUSA, E. M. B. D.; AZEVEDO, S. H. G.; MAGALHÃES, E. R.B. Tratamento de águas residuais da indústria do petróleo utilizando floculante nãoconvencional e flotação por ar dissolvido. XXV ENCONTRO NACIONAL DE TRATAMENTO DE MINÉRIOS E METALURGIA EXTRATIVA \& VIII MEETING OF THE SOUTHERN HEMISPHERE ON MINERAL TECHNOLOGY, Goiânia - GO, 2013.

SANTANA, C. R. Tratamento de água produzida através do processo de flotação utilizando a Moringa oleífera Lam como coagulante natural. 2009. 153f. Dissertação (Mestrado em Engenharia Química) - Núcleo de Pós Graduação em Engenharia Química, Centro de Ciências Exatas e Tecnologia, Universidade Federal de Sergipe, São Cristovão, Sergipe.

SILVA, C. R. R. Água produzida na extração de petróleo. 2000. 27f. Monografia (Curso de Especialização em Gerenciamento e Tecnologias Ambientais na Indústria) - Departamento de Hidráulica e Saneamento, Escola Politécnica, Salvador, Bahia. 